\title{
AS RELAÇÕES ENTRE OS SUJEITOS E O COMPARTILHAMENTO DA EXPERIÊNCIA: FORMAÇÕES PARA IMPLANTAÇÃO DO PROJETO 'MEMÓRIAS DE PARAISÓPOLIS'
}

\author{
RELACIONES ENTRE LOS SUJETOS Y LA \\ EXPERIENCIA DE COMPARTIR: FORMACIONES DE \\ EJECUCIÓN DEL PROYECTO 'PARAISÓPOLIS \\ MEMORIAS'
}

Simone Borges Paiva *

\section{RESUMO:}

Introdução: O presente relato é parte de tese de Doutoramento intitulada: Oficinas Intergeracionais: saberes e fazeres da experiência, mediação cultural e significação. Objetivo: Relata o processo de formação de educadoras para a implantação do projeto 'Memórias de Paraisópolis'.

Metodologia: Estruturado em forma de relato, o presente texto apresenta as ações empreendidas para permitir os processos de enunciação das narrativas da experiência pelas educadoras.

Resultados: As ações para enunciação e socialização da experiência ressignificam as práticas empreendidas no contexto investigado.

Conclusões: Os registros aqui apresentados indicam que o projeto Memórias de Paraisópolis, buscou oferecer condições para que os sujeitos pudessem contar suas histórias, dando-Ihes não apenas voz, mas também um espaço para socialização e partilha dessas vozes, inserindo-as em um contexto de formação e informação do qual o grupo de educadoras fazia parte.

Palavras-chave: Oficinas Intergeracionais, Mediação, Narrativas

\footnotetext{
*Doutora pelo Programa de Pós-Graduação em Ciência da Informação da Escola de Comunicações e Artes (USP). Professora Colaboradora do Departamento de Ciência da Informação da Universidade Estadual de Londrina (UEL). paiva.sb@gmail.com
} 
As relações entre os sujeitos e o compartilhamento da experiência: formações para implantação do projeto 'Memórias de Paraisópolis'

\section{INTRODUÇÃO}

Os grupos humanos desempenham um papel singular na formação dos sujeitos e, como lembra Vigotski ${ }^{1}$ (1986), as relações entre as pessoas atuam de maneira decisiva na formação social dos sujeitos. Sendo assim, o presente texto relata o processo de formação de educadoras vinculadas ao Programa Einstein, na Comunidade de Paraisópolis, e que, em parceria com a pesquisadora, desenvolveram o projeto Memórias de Paraisópolis por meio dos dispositivos "Oficinas Intergeracionais". As formações tinham como objetivo promover uma reflexão sobre a experiência ${ }^{2}$ e a sua comunicabilidade em contextos locais, de educação não formal, como o núcleo de Educação do Programa Einstein na Comunidade de Paraisópolis e dos dispositivos de informação e cultura, como a Estação do Conhecimento.

\section{DESENVOLVIMENTO}

\subsection{A importância das relações entre as pessoas na formação social dos sujeitos}

Um dos propósitos do manuscrito não publicado, Concrete Human Psychology (VYGOTSKY, 1986), é reafirmar o papel fundador das relações sociais na formação dos seres humanos, pois as relações sociais estão na base de todas as funções individualizadas. Estas têm como origem as formas de vida coletiva dos acontecimentos partilhados entre as pessoas. Nesse sentido, na perspectiva vigotskiana, o desenvolvimento é visto como cultural, como um processo de transformações que ocorre inicialmente para o outro e, posteriormente, para si, pois, segundo Vigotski, "[...] o caminho do objeto até a criança e desta até o objeto passa por outra pessoa." ${ }^{3}$

${ }^{1}$ Optamos, neste trabalho, empregar a grafia VIGOTSKI, mas preservamos, nas indicações bibliográficas, a grafia adotada em cada uma delas.

${ }^{2}$ No presente texto, a palavra experiência aparecerá com destaque em itálico, pois expressa o conceito investigado por Walter Benjamin em seus textos.

${ }^{3}$ (VIGOTSKI, 2000, p.24) 
As relações entre os sujeitos e o compartilhamento da experiência: formações para implantação do projeto 'Memórias de Paraisópolis'

O desenvolvimento é visto cultural, como um processo de transformação que ocorre, inicialmente, para o outro e, posteriormente, para si. De maneira que o caminho não está dado de forma direta, passa pelo outro, o qual, inserido na dinâmica, atua como mediador no desenvolvimento da criança e dos sujeitos em diferentes faixas etárias.

Queremos, portanto, pensar essa relação triádica no contexto da formação do grupo de educadoras que atuam no PECP e que colaboraram na criação e implantação do projeto 'Memórias de Paraisópolis', ao refletir, em parceria com a pesquisadora, sobre a atuação dos dispositivos, dos sujeitos e da comunidade, como mediadores, aqueles que se colocam entre as crianças e os adolescentes, auxiliando-os nos processos de construção do conhecimento. O presente tópico abordará elementos da teoria histórico-cultural, proposta por Vigotski, a qual preconiza uma relação dialética entre as funções psicológicas elementares e as funções psicológicas superiores, nesse sentido, a constituição psíquica do homem não se situa somente na ordem biológica, mas também na ordem cultural.

Interessante perceber como o autor, a partir da reflexão sobre a palavra história, estabelece relação com o desenvolvimento das funções psicológicas superiores, compreendendo que elas são governadas por leis históricas. Por isso, o que tornaria a mente humana única é o fato de que, tanto a história em sua perspectiva dialética quanto a história vista a partir do materialismo histórico, estão unidas em síntese e, a partir dessa síntese, a mente humana desenvolve-se. O estudo desse desenvolvimento requer, portanto, um método, e na visão do autor é o construtivismo este método, que implica duas variáveis:

Um método construtivista implica duas coisas: 1. Ele estuda construções em vez de estruturas naturais; 2. Ele não analisa, mas interpreta um processo (em oposição a um método de compreensão súbita, análise.) ${ }^{4}$ (VYGOTSKY, 1986, p.55, tradução nossa).

\footnotetext{
4 "A constructive method implies two things: (1) it studies constructions rather than natural structures; (2) it does not analyze, but construes a process (contra a method of grasping unexpectedly, analysis (...)." (VYGOTSKY, 1986, p.55)
} 
As relações entre os sujeitos e o compartilhamento da experiência: formações para implantação do projeto 'Memórias de Paraisópolis'

A partir da concepção de que a mente é governada a partir de uma síntese de processos históricos e que o construtivismo é o método que permite estudar 0 desenvolvimento das funções psicológicas superiores, pois estabelece o estudo das construções ao invés de focalizar apenas as estruturas naturais, Vigotski reafirma que a ação do ser humano, no meio social, tem na linguagem o seu principal elemento mediador, e é a partir dela que as relações humanas são estabelecidas. Nas palavras do autor, "[...] o problema do comportamento verbalizado é o problema central em toda a história do desenvolvimento cultural da criança." 5

Se o autor localiza no problema do comportamento verbalizado a questão central na história do desenvolvimento cultural das crianças, a relação entre os seres humanos tem início antes mesmo do processo de aquisição de linguagem, pois, segundo Vigotski, primeiramente os atos estariam orientados para os outros e, posteriormente, para si mesmos. O autor identifica, portanto, três estágios fundamentais no processo de desenvolvimento cultural. São eles o "[...] desenvolvimento em si, para os outros, e para si mesmo." 6

Com o intuito de exemplificar a relação entre os estágios de desenvolvimento, Vigotski apresenta como exemplo a seguinte situação, em que,

[...] um gesto demonstrativo - inicialmente é simplesmente um movimento de compreensão falho dirigido a um objeto e designando uma ação; então a mãe o compreende como uma instrução; e finalmente a criança começa a apontar. ${ }^{7}$ (VYGOTSKY, 1986, p.56, tradução nossa).

No exemplo apresentado pelo autor, tendo em vista diferentes estágios de desenvolvimento, a criança realiza movimentos que não são, a priori, gestos

\footnotetext{
5 "[...] the problem of verbalized behaviour is the central problem in the whole history of the cultural development of the child." (VYGOTSKY, 1986, p.56)

6 "[...]development in itself, for others, and for oneself." (VIGOTSKI, 1986, p.56)

7 "[...] a demonstrative gesture - at first it is simply a failed grasping movement aimed at an object and designating an action; then the mother understands it as an instruction; and finally, the child begins to point." (VIGOTSKI, 1986, p.56)
} 
As relações entre os sujeitos e o compartilhamento da experiência: formações para implantação do projeto 'Memórias de Paraisópolis'

demonstrativos. Eles se transformam em gestos graças à intervenção da mãe, que vê naquele movimento uma instrução, a indicação de um pedido realizado pela criança. Após tal intervenção, a criança compreenderá o sentido dado pela mãe e passará a apontar. Nesse sentido, o autor destaca:

Fica claro, portanto, que a apropriação ou internalização pela criança do universo cultural dos homens não é uma operação simples, que possa ser reduzida a um mero processo de aprendizagem. Não se trata, tampouco, de uma operação de simples transferência de práticas e conteúdos culturais do plano social ou externo para o plano individual ou interno, como pode deixar entender o conceito de internalização. Trata-se, ao contrário, de uma operação complexa de re-constituição (reprodução-criação) em e pela criança de algo já construído pelo gênero humano e que define a história dos homens. (PINO, 1993, p.22)

Logo, conclui Vigotski que "Nós nos tornamos nós mesmos através dos outros. [...] a essência do processo de desenvolvimento cultural consiste precisamente nisso." Ao introduzir o pressuposto de que nos tornamos nós mesmos por meio dos outros e afirmar que nesse princípio relacional está a essência do processo de desenvolvimento cultural, o autor reafirma o valor daquilo que ocorre no meio externo e que, ao longo do desenvolvimento, se transforma em funções psicológicas superiores. Nas palavras do autor: "[...] está claro porque tudo que é interno em funções superiores foi necessariamente externo em algum momento." 9 A razão para isso reside no fato de que, inicialmente, foi para outros o que hoje é para si mesmo.

Como diz Valsiner (1987), comentando Vygotsky, a criança nasce inserida num meio cultural significativo, feito de significações socialmente definidas e codificadas nos objetos e eventos que formam o meio concreto da criança através das ações daqueles que convivem com ela. Estas significações guiam o desenvolvimento da criança, mas não de maneira

8 "We become ourselves through others. "[...] the essence of the process of cultural development consists precisely in this." (VYGOTSKY, 1986, p.56)"

9 "[...] it is clear why everything that is internal in higher functions was necessarily once external" (VYGOTSKY, 1986, p.56). "[...] it was for others what today is for itself" (VYGOTSKY, 1986, p.56) 

implantação do projeto 'Memórias de Paraisópolis'

determinista, e servem de referência para ela e para o grupo social nas suas inter-relações. A internalização dessas significações culturais implica, porém, da parte da criança, sua re-elaboração em função dos seus próprios referenciais semânticos. Vygotsky chama isso de sentido pessoal das palavras, que ele contrapõe ao significado socialmente estabelecido. Dentro de tal meio culturalmente estruturado (significativo) e personalizado (pleno de sentido) a criança em desenvolvimento inventa (ou re-inventa, por imitação) novas formas de agir e de pensar, das quais só são retidas aquelas que acabam sendo aceitas pela criança e pelo seu meio social (VALSINER apud PINO, 1993, p.21-22).

É preciso, no entanto, atentar para o que Vigotski compreende como processo externo e cultural. Sob o ponto de vista do autor, o processo externo relaciona-se com o social, no sentido de que qualquer função psicológica superior é também "externa, quer dizer, social". Um social que:

[...] antes de se tornar uma função, foi a relação social entre duas pessoas. O meio de agir sobre si mesmo é inicialmente um meio de agir sobre outros e a ação de outros sobre a sua personalidade. (VYGOTSKY, 1986, p. 56, tradução nossa) ${ }^{10}$

Novamente, o valor da relação entre pessoas é indicado pelo autor como elemento-chave para a compreensão do desenvolvimento cultural e psicológico, em que a história do desenvolvimento das funções está inscrita nas interações socioculturais, na relação entre as pessoas, nos modos como atuam umas sobre as outras, em ações que se desenvolvem de si para o outro e vice-versa, em processos dinâmicos e simultâneos de apropriação de conhecimentos, de si e do mundo e de desenvolvimento pessoal e cultural.

Vigotski esboça uma lei para essa dinâmica, na qual postula que "[...] a relação entre funções psicológicas superiores foi em um momento anterior uma relação física entre pessoas. Eu me relaciono comigo do modo como as pessoas se relacionam comigo." ${ }^{11}$ O desenvolvimento das funções

\footnotetext{
10 "[...] before becoming a function, it was the social relation between two people. The means of acting upon oneself is first a means of acting on others and the action of others on one's personality." (VYGOTSKY, 1986, p.56)

11 "[...] the relation between higher psychological functions was at one time a physical relation between people. I relate to myself as people relate to me." (VYGOTSKY, 1986, p.56)
} 
As relações entre os sujeitos e o compartilhamento da experiência: formações para implantação do projeto 'Memórias de Paraisópolis'

psicológicas superiores está alicerçado, portanto, nas relações que os sujeitos estabelecem entre si, pois para compreender a si é preciso compreender os outros.

A linguagem é retomada pelo autor, especialmente a partir do uso da palavra no contexto das relações. Segundo Vigotski, as palavras regem as relações. No entanto, ao apoiar-se em estudos empreendidos por Janet sobre os modos como as palavras são comandos para os outros e estabelecem relações de poder entre os seres, o autor diz que "[...] a relação de funções psicológicas é geneticamente ligada a relações reais entre pessoas; regulação da palavra, comportamento verbalizado = poder - submissão" ${ }^{12}$, especialmente se vistos a partir de relações diretas ou relações mediadas entre as pessoas, em que as formas de comunicação verbal, entre adultos e crianças, se tornam, posteriormente, funções psicológicas.

$\mathrm{O}$ acesso ao universo dos signos marca, portanto, a passagem entre 0 nível de atividade prática infantil para as formas adultas de atividade mental. No processo de qualificar as relações entre as pessoas ou as formas de interação entre as pessoas, transformadas em funções psicológicas superiores, Vigotski diz, inicialmente, que se trata de uma relação física, quando juntas em interações, em sociabilidades recíprocas, em ações conjuntas, que transformam e utilizam instrumentos.

Em um segundo momento, Vigotski retoma a relação física entre as pessoas em associação com o desenvolvimento, incorporando ao contexto a questão do comportamento verbalizado. O outro age sobre o mundo por meio da linguagem. Temos uma interação física, associada a uma relação regulada pelo comportamento verbalizado, entre um adulto e uma criança, que se transforma em função psicológica superior. É importante destacar os modos relacionais pelos quais as pessoas interagem, mas é preciso recordar o que, no

12 "[...] the relation of psychological functions is genetically (developmentally) linked to real relations between people; regulation of the word, verbalized behaviour = power - submission." (VYGOTSKY, 1986, p.57) 
As relações entre os sujeitos e o compartilhamento da experiência: formações para implantação do projeto 'Memórias de Paraisópolis'

contexto construído por Vigotski, pode ser compreendido como social. Sendo assim, o autor esclarece que,

Aplicado ao nosso tema, a palavra social tem vários significados. (1) o mais geral - tudo o que é cultural é social: (2) um signo ou símbolo independente do organismo, tal como uma ferramenta, é um meio social; (3) todas as funções superiores evoluem em filogenia não biologicamente, mas socialmente; (4) o significado mais primitivo - o mecanismo de tal função é uma cópia do social. Eles são relações internalizadas de uma ordem social, transferidas para a personalidade individual. ${ }^{13}$ (VYGOTSKY, 1986, p.58, tradução nossa).

No trecho citado, o autor resgata os significados que a palavra social assume ao longo da sua teoria geral do desenvolvimento. Nela, o social relaciona-se com tudo o que é cultural. Um sinal ou símbolo, tal como uma ferramenta, são concebidos como meios sociais. E, por fim, o mecanismo de funcionamento das funções psicológicas é uma "cópia do social", reelaborado, contudo, pelo sujeito para, enfim, transformar-se em estrutura de personalidade individual. Nesse sentido, seguindo a abordagem histórico cultural, Vigotski estabelece que a natureza da personalidade dos indivíduos é social:

[...] na abordagem histórico-cultural, a construção de conhecimentos é concebida como processo constituído nas relações sociais, implicando o funcionamento interpessoal e a linguagem. $O$ conhecer envolve mediação pelo outro e produção de significados e sentidos em relação a objetos culturalmente configurados. (GÓES, 1995, p.23).

Para enfatizar a natureza social da personalidade dos indivíduos, Vigotski inspira-se em Marx e diz que "A natureza psicológica do homem é a totalidade das relações sociais transpostas para a esfera interior e tendo se

\footnotetext{
13 "Applied to our topic, the word social has many meanings. (1) the most general - all things cultural are social; (2) a sign or symbol independent of the organism, such as a tool, is a social means; (3) all higher functions evolve in phylogeny not biologically, but socially; (4) the crudest meaning - the mechanism of such function is a copy of the social. They are internalized relations of a social order, transferred to the individual personality." (VYGOTSKY, 1986, p.58)
} 
As relações entre os sujeitos e o compartilhamento da experiência: formações para implantação do projeto 'Memórias de Paraisópolis'

tornado funções da personalidade e formas da sua estrutura." ${ }^{14}$ A configuração psicológica do homem não se reduz, portanto, aos elementos biológicos ou mentais, mas, sim, é fruto do total das relações sociais modeladas para a esfera íntima, que as processa e as transforma em estruturas cognitivas de personalidade. Portanto, seja do ponto de vista do desenvolvimento psicológico, seja do ponto de vista do desenvolvimento cultural das crianças, a interação com os adultos representa a "[...] principal força motora de todo desenvolvimento (adulto e criança, aritmética, fala, etc.)." ${ }^{15}$

$\mathrm{Na}$ relação entre adultos, crianças e adolescentes, Vigotski identifica o papel importante que os primeiros desempenham na formação dos chamados conceitos cotidianos. Van der Veer e Valsiner (2014) explicam que estes são os conceitos adquiridos pelas crianças fora do contexto da instrução explícita e sistemática oferecida pela escola. Para Vigotski, os conceitos cotidianos nutrem relações com conceitos que são explicitamente apresentados por um mestre em contexto escolar, os chamados conceitos científicos. Os conceitos científicos, vinculados ao espaço escolar, uma vez associados aos conceitos do cotidiano, permitem "[...] uma reconceitualização do conhecimento existente em nível semântico." ${ }^{16}$ Nesse sentido, os conceitos cotidianos e científicos são parceiros em um inter-relacionamento complexo, e por isso,

[...] não se pode ensinar conceitos científicos a uma criança antes que seus conceitos cotidianos tenham atingido um determinado nível mínimo. Os conceitos científicos, portanto, têm sua base em conceitos cotidianos. (VAN DER VEER; VALSINER, 2014, p.296)

Percebemos, desse modo, que é a interação com membros mais maduros da cultura, possuidores de uma linguagem estruturada, que provoca 0 salto qualitativo para o pensamento verbal, sendo importante a manutenção

\footnotetext{
14 "The psychological nature of man is the totality of social relations shifted to the inner sphere and having become functions of the personality and forms of its structure." (VYGOTSKY, 1986, p.56)

15 "[...] principal driving force of all development (adult and child arithmetic, speech, etc)." (VYGOTSKY, 1986, p.59)

${ }^{16}$ (VAN DER VEER; VALSINER, 2014, p.296)
} 
As relações entre os sujeitos e o compartilhamento da experiência: formações para implantação do projeto 'Memórias de Paraisópolis'

das relações entre adultos e crianças e, especialmente, a imersão da criança em grupos com diferentes níveis de desenvolvimento. Sobre 0 desenvolvimento infantil, na perspectiva vigotiskiana, Luria (1988) diz que,

Desde o nascimento, as crianças estão em constante interação com os adultos, que ativamente procuram incorporá-las à sua cultura e à reserva de significados e de modos de fazer as coisas que se acumulam historicamente. (LURIA, 1988, p.27)

Nesse sentido, crianças e adultos atuam de forma distinta, e cabe ao adulto partilhar e, portanto, incluir a criança no universo cultural, no repertório de significados partilhados e nos modos de fazer historicamente constituídos. $A$ inclusão em tais realidades é fundamental para que a criança compreenda a si e aos outros. Nas palavras de Luria, "Os adultos, nesse estágio, são agentes externos servindo de mediadores do contato da criança com o mundo." ${ }^{17}$ Vale ressaltar, ainda, que, mesmo nos processos mediados por instrumentos, é possível identificar as influências das relações entre os seres humanos, pois, de acordo com o autor, "[...] uma operação instrumental é sempre uma ação social sobre si mesmo, usando o meio da comunicação social, e é revelada como uma relação social entre duas pessoas." ${ }^{18}$

Dizer, portanto, que nos tornamos nós mesmos por meio de um jogo dinâmico entre nós e os outros, nós e os dispositivos, os instrumentos, os sujeitos, as ordens sociais e culturais nas quais nos inscrevemos, é dizer, assim, que os seres humanos se constroem nas interações, ou seja, tanto a partir de suas próprias possibilidades, como das possibilidades dos outros e do mundo, tanto individual como socialmente, tanto objetiva como subjetivamente.

As investigações desenvolvidas por Vigotski nos auxiliam a compreender as dinâmicas existentes nos processos de desenvolvimento psicológico e a relação que elas mantêm com a cultura. Nesse sentido, os sujeitos são atores, adultos e crianças desempenham papéis importantes no desenvolvimento

\footnotetext{
17 (LURIA, 1988, p.27)

18 "[...] an instrumental operation is always a social action on oneself, using the means of social communication, and is filly revealed as a social relation between two people." (VYGOTSKY, 1986, p.62)
}

Inf. Prof., Londrina, v. 5, n. 2, p. $206-227$, jul./dez. 2016.

http:www.uel.br/revistas/infoprof/ 
As relações entre os sujeitos e o compartilhamento da experiência: formações para implantação do projeto 'Memórias de Paraisópolis'

individual e coletivo, sendo que 0 primeiro atua como mediador/formador/preparador da vivência sociocultural que será empreendida pelo segundo. Daí a importância de refletir sobre a atuação dos educadores não apenas como condutores de um processo de educação não formal, mas também, como aqueles que, como antecessores, podem mediar a interação das crianças com o mundo, tendo para isso, entre outros dispositivos, a linguagem.

Permitir que a experiência revele-se por meio da linguagem de modo que posso ser socializada, compartilhada, registrada e ressignificada, foram os pressupostos das ações relatadas a seguir.

\section{METODOLOGIA}

$\mathrm{Na}$ presente seção, serão apresentados os relatos das práticas formativas realizadas em 2013 e desenvolvidas junto com a equipe do PECP, destacados pela coordenação do Núcleo de Educação Cidadão para atuar no processo de construção do dispositivo "Oficinas Intergeracionais". Sendo assim, o grupo foi formado por 12 educadoras que coordenavam os grupos da Educação Cidadã, duas mediadoras que atuavam na Estação do Conhecimento Einstein, além da coordenação geral do NE, em um total de 15 profissionais do PECP. Juntas, pesquisadora e educadoras reuniram-se para refletir sobre a memória, a experiência no contexto de comunidades locais como Paraisópolis, além dos dispositivos que ali estão implantados, como o Núcleo de Educação e a Estação do Conhecimento Einstein.

Para tanto, foram oferecidas duas formações iniciais com objetivos específicos: a primeira delas teve como propósito compartilhar experiências, por meio da enunciação, da escuta e da socialização. A segunda, por sua vez, levou o grupo de educadoras a refletir sobre o enclausuramento institucional, social e pessoal que são impostos à experiência, impedindo a sua circulação e sua vinculação às dinâmicas do cotidiano.

Tais ações iniciais com a equipe Einstein foram essenciais ao planejamento do trabalho e antecederam a inclusão da comunidade nos 
processos. Era necessário compor e preparar a equipe e contar com sua experiência no processo de levantamento e percepção da realidade local, com suas especificidades, potencialidades e desafios. Ao mesmo tempo, era preciso formar bases comuns para formatação e implantação conjunta do trabalho. Oferecemos, assim, a seguir, a descrição pormenorizada desses encontros preparatórios de sensibilização, informação e formação, cujos resultados se mostraram de importância fundamental ao trabalho posterior.

\section{RESULTADOS}

\subsection{Primeiro Encontro Preparatório: "compartilhando, escutando e comunicando experiências"}

Benjamin (1994, p.37) diz que "[...] um acontecimento vivido é finito, ou pelo menos encerrado na esfera do vivido, ao passo que o acontecimento lembrado é sem limites, porque é apenas uma chave para tudo o que veio antes e depois." Com base em tal afirmação, iniciamos o processo de formação com as educadoras do Núcleo de Educação, do Programa Einstein na Comunidade de Paraisópolis, acreditando que o exercício da lembrança, realizado individualmente e coletivamente, poderia colaborar para aproximar o grupo da temática que orienta os projetos de memória desenvolvidos pelo COLABORI, como a Estação Memória: o sujeito e sua experiência como chaves para "o que veio antes e depois".

Dentre as questões apresentadas nessa fase, referimo-nos à própria Estação Memória, sua história, seus princípios teóricos e metodológicos, uma vez que nossa proposta estava vinculada a esse trabalho que era conhecido em linhas gerais pelo grupo, mas que necessitava ser apreendido de modo integral, inclusive com suas conexões com o trabalho desenvolvido pelo COLABORI/ECA/USP e PECP, ou seja, a Estação do Conhecimento Einstein.

Para tanto, um pequeno texto introdutório foi entregue ao grupo para leitura e discussão. Em seguida, buscou-se aproximar o grupo de educadoras das questões do projeto, posicionando-as como sujeitos dispostos a partilhar saberes e fazeres da experiência, alternando-se, assim, os papéis: ora eram 
As relações entre os sujeitos e o compartilhamento da experiência: formações para implantação do projeto 'Memórias de Paraisópolis'

narradoras, ora eram ouvintes, em uma mescla de perspectivas e de olhares sobre as reconstruções narrativas do grupo e dos sujeitos que ali estavam. Dessa forma, foi proposta ao grupo a atividade "compartilhando, escutando e comunicando experiências".

Depois de dividir o grupo em duplas, foi solicitado para cada uma das participantes vivenciar o que seria uma pequena entrevista. No decorrer da vivência em dupla, as educadoras também alternavam-se, ora relatando, ora ouvindo e buscando documentar por escrito aquilo que ouviam. As participantes fizeram o exercício da fala, da escuta, do registro da fala, com a tradução da oralidade para um formato de texto construído segundo o repertório pessoal da escriba, mas também atentando para formas de textos que pudessem alcançar as particularidades da falante.

Como não havia roteiro e não cabia orientação sobre o que deveria ser lembrado, o grupo, por vezes, manifestou insegurança. No entanto, as mediações da pesquisadora, por meio de conversas, tranquilizavam as participantes, ao deixar claro que não havia um tema norteador para as lembranças e que os fatos que deveriam ser lembrados naquele momento tocavam cada uma.

Encerrada esta fase, passou-se à socialização dos frutos dos processos das duplas. Se partilhar as experiências parecia, a princípio, desnecessário para alguns membros do grupo de educadoras, estruturado e atuante há tanto tempo na instituição, as falas iniciais revelaram o contrário. Fatos até então desconhecidos vieram à tona, abrindo possibilidades para que novas leituras e novas percepções surgissem. A importância da experiência, dos saberes possibilitados pela sessão de rememoração, começou a ser percebida pelo grupo que tem na linguagem, em suas diferentes manifestações, peça chave de seu fazer profissional, como mediadores de educação e cultura.

Vale ressaltar o embaraço produzido pelo fato de não haver uma pergunta, um tema norteador para as lembranças: o que devemos lembrar? Nesse sentido, percebeu-se que boa parte das experiências levantadas pelo grupo relacionava-se com o ambiente escolar, seja como aluno ou como educador. Na ausência de um tema norteador, o contexto em que a atividade 
As relações entre os sujeitos e o compartilhamento da experiência: formações para implantação do projeto 'Memórias de Paraisópolis'

estava sendo desenvolvida influenciou bastante os processos de rememoração. Todavia, um sentido novo estava presente nas rememorações: mesmo falando de experiências próximas, a criação de um ambiente discursivo acolhedor, aberto à fala e à escuta, agregava associações, sentidos novos ao fazer conhecido, integrando em um mesmo e rico processo, enunciação e enunciador, rompendo fragmentações comuns em nossa época entre os sujeitos e a linguagem.

Freire, referindo-se à escuta, chama a atenção para essa dimensão de resgate que os atos de comunicação portam, quando enraizados na vida:

Escutar é obviamente algo que vai mais além da possibilidade auditiva de cada um. Escutar, no sentido aqui discutido, significa a disponibilidade permanente por parte do sujeito que escuta para a abertura à fala do outro, ao gesto do outro, às diferenças do outro. (FREIRE, 2003, p.75)

Disponibilizar-se para a escuta da fala do outro, significou, naquele contexto, estar atento não só ao que estava sendo dito, mas também aos modos como cada uma contava suas lembranças, suas memórias, buscando compreender o contexto ao qual a fala da outra se vinculava. As educadoras registraram a dificuldade para realizar esse processo, especialmente em centrar-se na dupla e no que estava sendo contado, buscando silenciar as outras partilhas que ocorriam no espaço. Outro fato apontado pelas educadoras diz respeito ao valor da escuta e ao que ela representa para aquela que estava contando a sua história e suas memórias. Sobre o abrir-se para a fala e para o compartilhamento das lembranças, Freire nos diz: "O sujeito que se abre ao mundo e aos outros inaugura com seu gesto a relação dialógica em que se confirma como inquietação e curiosidade, como inconclusão em permanente movimento na História." (FREIRE, 1996, p.86).

\subsection{Segundo Encontro Preparatório: Os Cofres da Memória}

O segundo encontro preparatório com o grupo de educadoras do Núcleo de Educação do Programa Einstein na Comunidade de Paraisópolis teve, por 
As relações entre os sujeitos e o compartilhamento da experiência: formações para implantação do projeto 'Memórias de Paraisópolis'

princípio, retomar ações desenvolvidas no âmbito do Programa, relacionandoas à temática da memória e dos dispositivos de memória, tal qual a Estação Memória. Para tanto foi necessário desenvolver conversas com a coordenação do núcleo, com o intuito de compreender como a instituição cuidava dos seus acervos documentais e dos "saberes da experiência" de suas equipes.

$\mathrm{Na}$ dimensão documental, verificamos os processos para registro e documentação das ações desenvolvidas no âmbito do Núcleo de Educação Cidadã, bem como a circulação do material de modo a permitir o estabelecimento de vínculos entre os trabalhos desenvolvidos no passado e as ações que estavam em desenvolvimento no presente. No que concerne à dimensão dos saberes da equipe, procuramos saber dos canais para a circulação da experiência profissional de cada educador e o estabelecimento de mecanismos para socialização dessas experiências. Ao final das conversas com a coordenação, foi possível identificar a necessidade de estabelecer ações concretas no sentido de promover a circulação dos acervos documental e do grupo, inserindo-os na rotina do Núcleo.

Em seguida, realizou-se o planejamento do segundo encontro. Para isso, tomamos como inspiração Hannah Arendt, que aponta uma lacuna entre o passado e o futuro em sua relação com a crise contemporânea pois,

Seja como for, é à ausência de nome para o tesouro perdido que alude o poeta ao dizer que nossa herança foi deixada sem testamento algum, $\mathrm{O}$ testamento, dizendo ao herdeiro o que será seu de direito, lega posses do passado para um futuro. Sem testamento ou, resolvendo a metáfora, sem tradição - que selecione e nomeie que transmita e preserve que indique onde se encontram os tesouros e qual o seu valor - parece não haver nenhuma continuidade consciente no tempo, e, portanto, humanamente falando, nem passado nem futuro, mas tãosomente a sempiterna mudança do mundo e o ciclo biológico das criaturas que nele vivem.

Para que o presente possa usufruir dessa herança do passado é preciso que a memória seja articulada e retomada, com o fito de construirmos uma história e, dessa forma, fazer uso do "tesouro perdido". Recuperar o passado é uma primeira garantia de um sentido para o presente. Ao recorrermos a memória dos relatos e testemunhos das épocas passadas, estamos transformando essas narrativas em história, fazendo 
As relações entre os sujeitos e o compartilhamento da experiência: formações para implantação do projeto 'Memórias de Paraisópolis'

com que um amontoado de fatos ganhe sentido. (ARENDT, 2003, p.31)

O segundo encontro de formação buscou compreender a tradição educacional, seus valores e princípios por meio do resgate de testemunhos da equipe de profissionais que atuam no contexto do Núcleo de Educação, de modo a, como nos diz Arendt, tirar do cofre aquelas lembranças, inserindo-as em uma ação que é contínua e conecta o passado com o presente. Ao incorporar ao processo de formação e de sensibilização esses elementos, desejávamos levantar questões com a equipe referentes às dimensões do trabalho com memórias, enfatizando, naquele momento, o resgate dos "saberes da experiência", decorrentes das lembranças profissionais, de projetos e de ações desenvolvidos pela equipe, refletindo de que maneira esses projetos nutriam relação com as ações do presente.

A primeira parte do encontro foi dedicada à leitura e discussão de poesias, aproximando o grupo à temática que seria discutida no encontro. Entre os textos utilizados, destacamos:

"De onde vêm as histórias?

Elas não estão escondidas como tesouro na gruta de Aladim ou num baú que permaneceu no fundo do mar.

Estão perto, ao alcance de sua mão... Abra os olhos e apure os ouvidos. É só prestar atenção. Ao pintor que, do alto da escada, com seu gorro de jornal, vai colorir as paredes da casa. Ao padeiro que hoje se inspirou e fez pães com forma de dragão e tartaruga (não passe indiferente pela vitrine). Você testemunha grandes e pequenos episódios que estão acontecendo a sua volta. Um dia será chamado a contar também. Então

verá que o tecido das vidas mais comuns é atravessado por um fio dourado: esse fio é a história." (BOSI, 2003, p. 51)

As leituras apresentadas ao grupo permitiram refletir sobre a origem das histórias e como elas não estão associadas apenas a figuras de ficção. Os 
sujeitos, nos variados espaços sociais, são protagonistas de suas experiências e das histórias da comunidade da qual fazem parte. E, histórias aparentemente distintas nutrem relações sutis entre si, e só um olhar mais atento, o olhar curioso de que tanto nos fala Freire, é capaz de perceber as sutis relações entre os sujeitos, suas histórias e comunidades.

Para o segundo momento do encontro, reservamos uma atividade prática em que cada educadora seria convidada a pensar sobre o percurso da sua atuação profissional, vinculada ao Núcleo de Educação e à Estação do Conhecimento Einstein. As educadoras receberam folha de papel e lápis e com eles deveriam representar uma linha do tempo cuja temática seria os projetos e ações desenvolvidos junto ao Núcleo de Educação e/ou Estação do Conhecimento Einstein. Ao final, refletiríamos sobre a linha de tempo de cada educadora e como as ações individuais se relacionam com o coletivo e, além disso, se há uma manutenção do passado no presente, se os projetos desenvolvidos no passado são, de alguma forma, inspiração para os trabalhos desenvolvidos na atualidade.

\section{CONSIDERAÇÕES}

Em função da atividade da primeira parte, as educadoras acabaram dando à segunda o título de "Entre o fio e a linha do tempo: refletindo sobre o percurso profissional", em sinal de apropriação e de interesse do que haviam feito no primeiro momento. As educadoras, individualmente, iniciaram o trabalho de produção de suas linhas do tempo e, novamente, a ausência de uma temática específica provocou inquietação no grupo. Houve uma delimitação, uma restrição ao espaço profissional e, no mais, cada educadora teria que explorar seu passado profissional. Foi possível observar olhares inquietos que aguardavam direções, sugestões no sentido de saber o que deveriam lembrar. Entretanto, a atividade seguia, tendo por referência o homem descrito por Benjamin em seu texto Escavando e recordando: 

implantação do projeto 'Memórias de Paraisópolis'

Quem pretende se aproximar do próprio passado soterrado deve agir como um homem que escava. Antes de tudo, não deve temer voltar sempre ao mesmo fato, espalhá-lo como se espalha a terra, revolvê-lo como se revolve o solo. Pois 'fatos' nada são além de camadas que apenas à exploração mais cuidadosa entregam aquilo que recompensa a escavação. (BENJAMIN, 1995, p. 239).

Buscávamos, portanto, levar o grupo a se lançar na aventura da escavação do seu passado profissional e dele extrair fatos, não fornecendo amarras, estruturas rígidas, pois, como diz Bergson, buscávamos vivenciar uma atividade prática na qual fosse possível distanciar-se do presente para,

[...] poder abstrair-se da ação presente, é preciso saber dar valor ao inútil, é preciso querer sonhar. Talvez apenas o homem seja capaz de um esforço desse tipo. Também o passado que remontamos deste modo é escorregadio, sempre a ponto de nos escapar, como se essa memória regressiva fosse contrariada pela outra memória, mais natural, cujo movimento para diante nos leva a agir e a viver. (BERGSON, 1999, p.90)

[...] Essa lembrança espontânea, que se oculta certamente atrás da lembrança adquirida, é capaz de revelar-se por clarões repentinos: mas ela se esconde, ao menor movimento da memória voluntária. (BERGSON, 1999, p.96)

Entre o esforço da escavação apontado por Benjamin e os clarões repentinos dos quais nos fala Bergson, observamos as educadoras no desenvolvimento da atividade. Recorriam ao repertório pessoal, ora lançandose em movimento inquisidor de si, ora sendo surpreendidas por lembranças escorregadias. Recorriam a anotações, pequenas informações nas agendas de trabalho, buscando o grupo, interrogando o outro sobre o passado que os unia e que, uma vez partilhados, recuperavam forma e sentido.

Finalmente, o exercício da construção das linhas chegou ao fim e passamos, então, a refletir sobre o processo e sobre o material que foi produzido pelas educadoras. Refletimos sobre a inquietação inicial relacionada ao que lembrar e, como, ao abandonarem o pressuposto de uma orientação mais clara sobre o que deveriam lembrar, as educadoras puderam investigar suas trajetórias, localizando experiências com as quais tinham um forte vínculo afetivo: o trabalho que mais gostaram, o momento mais emocionante, a maior 
frustração, etc. Houve também aquelas cuja inspiração foi estimulada por meio dos registros produzidos, da consulta à agenda e dos fatos descritos, utilizando-os como referência, mas agregando a eles detalhes, significados e contextos que escapavam ao registro escrito.

Da mesma forma, houve momentos em que o grupo atuou como apoio no processo de reconstrução de um dado que parecia desprovido de sentido, levando-nos, assim, a convidar o grupo a refletir sobre as fontes de informação que estavam ali implicadas: o sujeito, seu repertório pessoal, os registros documentais, os participantes do grupo ali presentes etc. O conjunto das fontes disponíveis permitiu ao grupo perceber que lembrar é ação e interlocução é trabalho. Implica, portanto, uma atitude perante as fontes, nas palavras de Eclea Bosi, pois "Na maior parte das vezes, lembrar não é reviver, mas refazer, reconstruir, repensar, com imagens e idéias de hoje, as experiências do passado. A memória não é sonho, é trabalho." (BOSI, 1994, p.55).

Benjamin, Bergson e Bosi indicam que rememorar é uma interpretação subjetiva das e entre as experiências cotidianas, com as vivências congeladas e perdidas no passado. A memória não estaria isolada; ela encontra-se distribuída e inserida no contexto em que estamos. Sendo assim, a troca com o outro e a colaboração dele podem auxiliar no processo de rememoração.

Encerramos o segundo encontro de formação para as educadoras concluindo um ciclo inicial que se propôs a sensibilizar a equipe para a temática e os princípios teóricos que serviriam de base para a criação do Projeto Memórias de Paraisópolis: o sujeito, suas experiências e os saberes delas resultantes, além do valor que o todo representa para orientar as ações no presente.

Ao longo dos encontros preparatórios, destacamos o educador como sujeito portador de experiência e como sendo aquele que pode, por meio da sua trajetória de vida, de formação, de saberes e fazeres, educar outros sujeitos e os desafiarem a agir no mundo. Ao final, lembramos ao grupo que a Estação Memória, enquanto dispositivo cultural, alerta também para uma voz silenciada pela sociedade, fato narrado por Edmir Perrotti, seu criador, em evento promovido pelo SESC. 
Concebi o projeto "Estação Memória" a partir da fala de uma velhinha que assistia na Rede Globo ao seriado Anarquistas, graças a Deus, baseado no livro de Zélia Gattai. A senhora acompanhava o seriado televisivo com interesse, vendo aparecer diante dela, dias após dias, a avenida Paulista e seus arredores. "É ótimo", dizia ela. "Estou adorando. Tanto, que estou até lendo o livro". Seu interesse, no entanto, não escondia uma frustração: "Tem o seguinte. O seriado só conta a história de quem vivia lá em cima, perto da Avenida Paulista. Nós que vivíamos aqui embaixo, na beira do rio, não aparecemos em lugar nenhum; nós não contamos nossas histórias, nós não temos vez nem voz. Um dia eu ainda escrevo um livro também sobre os daqui de baixo". Com impressionante simplicidade e lucidez, aquela senhora apontava um problema grave e complexo, relacionado à ordem social dos discursos. Referia-se à histórica e gritante desigualdade reinante na ordem simbólica do país; lastimava-se por aqueles que trabalharam, que fizeram a cidade, mas que não têm voz pública, ou seja, condições de contar seus feitos, sua visão dos fatos para o espaço amplo da pólis." (PERROTTI, p.131, 2006)

Portanto, o projeto Memórias de Paraisópolis buscou oferecer condições para que os sujeitos pudessem contar suas histórias, dando-Ihes não apenas voz, mas também um espaço para socialização e partilha dessas vozes, inserindo-as em um contexto de formação e informação do qual o grupo de educadoras fazia parte. As enunciações elaboradas pelas participantes permitiram que, caminhos antes trilhados, fossem revistos, dessa vez, orientados pela experiência de quem os viveu.

\section{REFERÊNCIAS}

BENJAMIN, W. Experiência e Pobreza. In: BENJAMIN, Walter. Magia e Técnica, Arte e Política. São Paulo: Brasiliense, 1994. (Obras Escolhidas, volume I).

BENJAMIN, W. O Narrador. Considerações sobre a obra de Nikolai Leskov. In: BENJAMIN, W. Magia e Técnica, Arte e Política. São Paulo: Brasiliense, 1994. (Obras Escolhidas, volume I).

BERGSON, H. Matéria e memória. São Paulo: Martins Fontes, 1999. 
As relações entre os sujeitos e o compartilhamento da experiência: formações para implantação do projeto 'Memórias de Paraisópolis'

BOSI, E. Memória \& sociedade: lembrança de velhos. Companhia das Letras: São Paulo, 1994.

BOSI, E. O tempo vivo da memória: ensaios de Psicologia Social. São Paulo: Ateliê Editorial, 2004.

BOSI, E. Velhos amigos. São Paulo: Companhia das Letras. 2003

GOES, M. C. R. de. A construção de conhecimentos: examinando o papel do outro nos processos de significação. Temas psicol., Ribeirão Preto , v. 3, n. 2, ago. 1995. Disponível em

<http://pepsic.bvsalud.org/scielo.php?script=sci_arttext\&pid=S1413389X19950002000 04\&lng=pt\&nrm=iso $>$. acessos em 15 mar. 2015.

GOES, M. C. R. de. Os modos de participação do outro nos processos de significação do sujeito. Temas psicol., Ribeirão Preto , v. 1, n. 1, abr. 1993 . Disponível em $<$ http://pepsic.bvsalud.org/scielo.php?script=sci_arttext\&pid=S1413389X19930001000 02\&lng=pt\&nrm=iso >. Acesso em 27 mar. 2014.

LURIA, A.R. Vigotskii. In: VIGOTSKII, L. S.; LURIA, A.; LEONTIEV, A. N. Linguagem, desenvolvimento e aprendizagem (coletânea de textos). São Paulo: Ícone, 1988. p. 21-38.

PINO, Angel L.B. Processos de significação e constituição do sujeito. Temas psicol., Ribeirão Preto , v. 1, n. 1, abr. 1993 . Disponível em $<$ http://pepsic.bvsalud.org/scielo.php?script=sci_arttext\&pid=S1413389X1993000100004\&lng=pt\&nrm=iso >. Acesso em 15 mar. 2015.

PINO, Angel L.B. Processos de significação e constituição do sujeito. Temas psicol., Ribeirão Preto , v. 1, n. 1, abr. 1993 . Disponível em $<$ http://pepsic.bvsalud.org/scielo.php?script=sci_arttext\&pid=S1413389X1993000100004\&lng=pt\&nrm=iso $>$. acessos em 15 mar. 2015.

VAN DER VEER, R. ; VALSINER, J.. Vygotsky: uma síntese. São Paulo: Loyola, 2014.

VIGOTSKI, L. S. A formação social da mente. São Paulo: Martins Fontes, 2000.

VIGOTSKII, L. S. Aprendizagem e desenvolvimento intelectual na idade escolar. In: VIGOTSKII, L. S.; LURIA, A.; LEONTIEV, A. N. Linguagem, desenvolvimento e aprendizagem. São Paulo: Ícone, 1988. p.103-118

VYGOTSKY, L.S. Pensamento e linguagem. São Paulo: Martins Fontes, 2008.

VYGOTSKY, L.S. Concrete Human Psychology. In: Psikhologiya, 1986, n. 1, pp. 5164. Disponível em: < http://lchc.ucsd.edu/mca/Paper/Vygotsky1986b.pdf>. Acesso em: 21 mar. 2014. 
As relações entre os sujeitos e o compartilhamento da experiência: formações para implantação do projeto 'Memórias de Paraisópolis'

\section{Title}

The relations between the subjects and the sharing of the experience: formations for implementation of the project 'Memories of Paraisópolis'

\section{Abstract:}

Introduction: The present report is part of a $\mathrm{PhD}$ thesis entitled: Intergenerational Workshops: knowledge and experience, cultural mediation and meaning.

Objective: It reports the formation process of educators for the implementation of the project 'Memories of Paraisópolis'.

Methodology: Structured in the form of an account, the present text presents the actions undertaken to allow the processes of enunciation of the narratives of the experience by the educators.

Results: The actions for enunciation and socialization of the experience re-signify the practices undertaken in the investigated context.

Conclusions: The records presented here indicate that the 'Memories of Paraisópolis' project sought to offer the conditions so that the subjects could tell their stories, giving them not only a voice but also a space for socializing and sharing these voices, inserting them in a context Training and information on which the group of educators was a part.

Keywords: Intergenerational workshops. Mediation. Narratives.

\section{Titulo}

Relaciones entre los sujetos y la experiencia de compartir: formaciones de ejecución del proyecto 'Paraisópolis Memorias'

\section{Resumen:}

Introducción: Este informe es parte de la tesis doctoral titulada Intergeneracional Talleres: el conocimiento y la experiencia práctica, la mediación cultural y significado.

Objetivo: Informan el proceso de formación educadores para la ejecución del proyecto 'Memorias Paraisópolis'.

Metodología: Estructurado en forma de informes, este texto se presentan las medidas adoptadas para permitir la enunciación procesa narrativas de experiencia por los educadores.

Resultados: Las acciones para la enunciación y prácticas experiencia de socialización resignificar realizadas en el contexto investigados

Conclusiones: Los registros presentados aquí indican que el proyecto Paraisópolis Memorias trató de ofrecer condiciones para que los sujetos podían contar sus historias, dándoles no sólo voz, sino también un espacio para socializar y compartir estas voces, colocándolos en un contexto la formación y la información que el grupo de educadores era parte.

Palabras clave: Talleres intergeneracionales. La mediación. Narrativas.

Recebido em: 25.08.2016

Aceito em: 30.11.2016

Inf. Prof., Londrina, v. 5, n. 2, p. 206 - 227, jul./dez. 2016.

http:www.uel.br/revistas/infoprof/ 